\title{
MEDFASH (Medical Foundation for HIV \& Sexual Health)
}

\author{
Susan Quilliam
}

Freelance Writer, Broadcaster, Consultant and Trainer, Cambridge, UK

\section{Correspondence to} Ms Susan Quilliam; susan@susanquilliam.com; http://www.susanquilliam.com

Received 13 May 2015 Accepted 13 May 2015

\section{CrossMark}

To cite: Quilliam S. J Fam Plann Reprod Health Care 2015;41:238-239.

\section{WHO ARE YOU?}

MEDFASH (Medical Foundation for HIV \& Sexual Health) is an independent charity dedicated to quality in sexual healthcare including HIV.

We began in 1987 when individuals within the British Medical Association (BMA) became concerned at the level of fear around HIV that was prevalent in the 1980s. There was a public health crisis and we wanted to comment on the underlying ethical issues, build confidence among healthcare professionals, and offer education both to professionals and policymakers.

Now we work with experts from a range of disciplines to promote understanding and good practice in sexual and reproductive healthcare (SRH), still with a strong strand of work on HIV. Our mode of operation is largely projectbased, responding to current needs.

We are governed by a board of trustees with a small number of employed staff based in our offices at BMA House in London, UK. We also use independent consultants and contractors with relevant expertise, and collaborate with partner organisations.

\section{WHAT SERVICES DO YOU OFFER?}

We provide a number of services, primarily focused on publications, policy reviews, education and research. Central is our monthly Sexual Health of HIV Policy eBulletin, giving the headlines of key developments in policy relevant to our topic areas at national and local levels. We launched this in late 2012 and aim to give our readers "all the information in one place". The eBulletin is aimed at our main audience - healthcare professionals and policymakers - but is also relevant to voluntary organisations and patient groups.

We produce other publications aimed at educating clinicians such as our booklet HIV in Primary Care, and a sister booklet for non-HIV specialists in secondary care, new editions of which will appear in 2015. We also produce policy standards documents, such as those for the management of sexually transmitted infections, on which we worked closely with the British Association for Sexual Health and HIV (BASHH). We are particularly proud of the development of Making it Work: A Guide to Whole System Commissioning for Sexual Health, Reproductive Health and HIV, commissioned and published by Public Health England in September 2014.

We also carry out policy reviews, for example of the previous national sexual health and HIV strategy in England. For such projects we undertake workshops with key groups, and use these to inform publications. We further influence policy by participating in campaigns and publishing joint position statements.

Our work has resulted in the development and running of training courses. One of the key directions in recent years has been the Sexual Health in Practice (SHIP) courses, originally developed by the sexual health promotion team in Birmingham, that we run for general practitioners (GPs) and practice nurses. They are delivered by the GPs themselves and provide knowledge and practical strategies for frontline staff. In 2014 we also launched an educational webtool on HIV for general practice, HIV TIPs, available free on our website.

We have developed a number of European Centre for Disease Prevention and Control (ECDC) publications, including a mapping report on HIV/STI prevention in the context of sexual health in the European Union (EU) and European Economic Area (EEA), and ECDC guidance on increasing uptake and effectiveness of HIV testing in the EU. We are currently working with UK and European partners on an EU-funded project to pilot indicator conditionguided HIV testing. 


\section{HOW ARE YOU FUNDED?}

Our individual projects are almost all funded by statutory public health bodies, educational grants from pharmaceutical companies, or by health organisations, including the Faculty of Sexual \& Reproductive Healthcare. Our training courses are usually commissioned externally. We also tender for work offered by external sources, and receive donations from a range of supporters.

Funding itself, in these times of economic belttightening, is our biggest challenge. We want to continue to produce work of the highest quality, but this requires money as well as time and enthusiasm.

\section{HOW DO YOU DISTINGUISH YOURSELVES FROM OTHER ORGANISATIONS IN THE FIELD?}

We occupy a particular place in sexual health because we are not a service provider and so can work on issues with a range of different stakeholders; we are known for our ability to bring together stakeholders and facilitate consensus. We are also unusual in working across the range of SRH issues and HIV. We are authoritative - our historic and current links with the BMA give us credibility to add to the quality of our work - but despite this link, we are independent.

\section{WHAT DO YOU WANT TO SAY TO JOURNAL READERS?}

Our main message is that we understand your issues and the challenges you face, and we want to offer support.
We are keen to initiate dialogue with all those involved in the SRH arena. We would love you to tell us what issues you are currently identifying, as a lead-in to ideas for new projects that we can work on. We are also always keen to hear from those wanting to work with us as consultants.

As a first step, we encourage Journal readers to check out our website and sign up to our monthly eBulletin. And of course, if you would like to support the work we do, please visit our website and make a donation.

\section{FURTHER INFORMATION}

Who: MEDFASH (Medical Foundation for HIV \& Sexual Health)

Address: BMA House, Tavistock Square, London WC1H 9JP, UK

Telephone: +44 (0)20 73836345

Website: http://www.medfash.org.uk

Enquiries: enquiries@medfash.bma.org.uk

Competing interests None declared.

Provenance and peer review Not commissioned; internally peer reviewed.

Editor's note This article is one in a series of occasional articles on key health organisations worldwide. The Journal would be pleased to hear from other organisations, particularly those based outside the UK, which would like to be similarly profiled.

\section{FACULTY OF SEXUAL \& REPRODUCTIVE HEALTHCARE MEMBERSHIP EXAMINATION}

The Membership Examination (MFSRH) consists of:

Part 1 Single Best Answer paper (SBA)

The London-based examination is held annually in April and October. Applications for the Friday $\mathbf{1 6}$ 0ctober 2015 examination must be received by 1 July 2015. The syllabus for the Part 1 examination is on the FSRH website.

\section{Evidence Based Commentary (EBC)}

Candidates can view the released topic and candidate guidance notes for EBC on the Faculty website. There is an absolute deadline of $\mathbf{3 1}$ August $\mathbf{2 0 1 5}$ to submit the EBC on this topic. You can submit an EBC before applying to enter the Part 1 examination.

Part 2 Examination (CRQ, EMQ, OSCE)

Applications for the MFSRH Part 22016 (date and venue to be confirmed) must be received by 10 January 2016.

Further information and the Part 2 Syllabus are on the FSRH website. The qualification is subject to re-certification every 5 years. For the current MFSRH Examination Regulations, information on all components of the MFSRH examination and application forms, please visit the Faculty of Sexual and Reproductive Healthcare website: www.fsrh.org (Examinations) or contact Abigail Wright: abigail@fsrh.org 